\title{
The Qualitative-Quantitative 'Disparities' in Social Science Research: What Does Qualitative Comparative Analysis (QCA) Brings in to Bridge the Gap?
}

\author{
Orest S. Masue ${ }^{1}$, Idda L. Swai ${ }^{1} \&$ Mackfallen G. Anasel ${ }^{1}$ \\ ${ }^{1}$ School of Public Administration and Management, Mzumbe University, Morogoro, Tanzania \\ Correspondence: Orest S. Masue, School of Public Administration and Management, Mzumbe University, P.O. \\ Box 2 Mzumbe, Morogoro, Tanzania. Tel: 255-7-3293-0114; 255-6-5261-4606. E-mail: orest.masue@gmail.com
}

Received: May 10, 2013 Accepted: May 28, 2013 Online Published: August 1, 2013

doi:10.5539/ass.v9n10p211 URL: http://dx.doi.org/10.5539/ass.v9n10p211

\begin{abstract}
There are explicit methodological tensions among researchers in the qualitative and quantitative tracks of social science research. In this paper, (1) we highlight the tensions by making a comparison of the two traditions in terms of their ontological and epistemological paradigms, strengths and weaknesses. Then, (2) we examine the possibility of mediating the methodological tensions through the use of Qualitative Comparative Analysis (QCA) methodology. Our conclusions are that (1) both qualitative and quantitative research traditions are equally scientific and relevant to the social science research, and so, choice can be made to use either of the two approaches or combine them depending on the nature and purpose of the study. We also argue (2) that although the attempt to resolve the qualitative- quantitative tensions through QCA methodology is promising, QCA should not be regarded as a competing but a complementary approach to the two.
\end{abstract}

Keywords: social science research, qualitative research, quantitative research, ontology, epistemology, QCA

\section{Introduction}

Quantitative and qualitative research styles in social science research are hotly debated as to which one of them is more appropriate than the other in meeting the criteria of good research, such as establishing causal inference and achieving generalizability (Ercikan \& Roth, 2006). While some quantitative researchers have strong belief on systematic statistical analysis as the only way to establish causal relationship and achieve generalization in social sciences research, some in the qualitative track challenge this claim on the grounds that social phenomena are complex and therefore, cannot effectively be understood through the use of quantitative approaches. In addition, social phenomena are context specific and therefore can best be studied using context-sensitive approaches such as case study. In this paper, we attempt to reconcile between the two traditions of social research by bringing in QCA as a mid-way approach that seeks to address the inadequacies of each of the two approaches in social science research. More specifically, we discuss in the paper the strength of QCA in establishing causality, handling causal complexity and increasing generalizability.

\section{Qualitative vs. Quantitative Approaches in Social Research}

It is not our intention to dwell much on the tensions between qualitative and quantitative approaches in social research. However, we think it is important to open up with a quick summary of some fundamental differences in orientation between the two approaches right here at the beginning so that when we proceed to the discussion on the role of QCA in bridging the two (which is the main focus of this paper); it can clearly be understood as to what aspects in each of the two traditions QCA attempts to resolve. We will start with qualitative research and then proceed to quantitative approach before entering into QCA as a midway approach to reconciling the methodological disparities between the two.

\subsection{Philosophical Underpinnings of Qualitative Research}

As the term suggests, 'qualitative research approach' seeks to explain social phenomena in qualitative terms, i.e. it employs approaches that do not rely on 'numerical measurements' (King, Keohane, \& Verba, 1994:4). Researchers in this tradition use qualitative methods to collect and analyze data (Long \& Godfrey, 2004), and so they focus on visual and verbal (conceptual or thematic) rather than numerical data handling techniques to draw 
out the subjects' knowledge and perceptions and explore the context in terms of 'social settings' and 'culture' (Long \& Godfrey, 2004:83). Qualitative research thus envisages gaining a deep understanding of a specific case (such as an organization, a group or a small number cases); rather than a superficial description of a large sample of a population. It seeks to provide an explicit interpretation of specific aspects of a particular unit of inquiry (i.e. a case), such as structure, order, and broad patterns, hence, it is also referred to as 'interpretative research (Smith, 1983:6). Being interpretative, qualitative research strives to understand outcomes in 'individual cases'; thus, it is also called 'case-oriented research' (Ragin, 1999 b.:1137). In qualitative research, the questions of 'why' and 'how' are important. That is to say, it invests in seeking and providing an in-depth understanding on why things are the way they are in our social surroundings and why people behave the way they do (Marshall \& Rossman, 1999). Also, it applies methods that seek to provide in-depth views on how society is thought to operate and the related historical, cultural, social, and political influences that affect how decisions are made and the like (Dharamsi \& Scott, 2009). Qualitative researchers for example, may attempt to identify the causes of historical events and/or policy trends such as the World War I, the collapse of Soviet Union, creation of especially generous welfare states, and so on. It moves backwards by first identifying the cases and their outcome, and then proceeds to their causes. In other words, what case-oriented research seeks to achieve is to identify causes of outcomes for each of the cases that fall within the scope of the theory under investigation. This is what is called 'cause-of-effects' approach to explanation (Mahoney \& Goertz, 2006:228-231). With regard to how analysis is approached, qualitative research analyze cases holistically, where each individual case is viewed as an interpretable whole. This is to say in other words that case-oriented researchers consider cases as 'meaningful but complex configurations of events and structures' (Ragin, 1997:125); where their concern is not to establish relationships between variables but to understand a complex unity (Della Porta, 2008).

Qualitative research approach also differs from quantitative research approach in the way phenomena or subjects are approached. While quantitative social research seeks to study social phenomena in a controlled environment, qualitative social research strives to understand the social world from the point of view of the actors/subjects. In line with that, qualitative research employs contextual understanding so that social phenomena /behavior is conceived in the context of meaning systems employed by the by a particular group or society (Mishler, 1979). To fulfill the criteria for contextual understanding, '...data tend to be collected in the field as opposed to laboratories or other researcher-controlled situations' (Atkinson, 1988; Bogdan \& Biklen, 1998:3; Garfinkel, 1967). In that view, qualitative researchers do not attempt to introduce treatments and manipulation of variables, or impose their own operational definitions of variables on the participants. Instead, it provides for the meaning to emerge from the participants/subjects (Mouton, 1986; Taylor, 1985). Qualitative research is usually case-sensitive; in that it is flexible enough to adjust to the setting. Owing to flexibility, concepts, data collection tools and data collection methods in qualitative research can necessarily be adjusted as the research proceeds. Qualitative research approach uses methods such as participant observation, documentary analysis, in-depth interview, ethnography, focus group discussion and life histories to collect data (Frankfort-Nachmias \& Nachmias, 1992; Long \& Godfrey, 2004; Ragin, 1999 a).

Regarding approaches to measurement, qualitative research differs largely from quantitative research. Unlike the quantitative research which uses indicators of concepts as measures, qualitative research is more knowledge centered and tends to be more grounded in empirical evidence and also more 'iterative' in nature (Ragin, 2007:7). In other words, there is continual interplay between concept formation and measurement on the one hand, and research strategy on the other (Glaser \& Strauss, 1967). The researcher begins with orienting ideas and broad concepts, and employs empirical cases to improve and elaborate concepts (Becker 1958); a process involving an iterative back-and-forth movement between ideas and evidence (Katz, 1982; Ragin, 1994), where researchers specify and refine their empirical indicators and measures. Measurement in qualitative research is more case oriented than it is in quantitative research, i.e. it pays more attention to the details of cases. In case-oriented research, the conceptual focus is on specific cases, for example, the 'developed countries,' the 'developing countries' and so on (Ragin, 2007:8). Therefore, in the case-oriented perspective, the key focus is on sets of cases, whose members can be identified and studied individually; for example, individual members of the set of developed countries (Ragin, 2007).

Let us consider how qualitative research deals with 'lack of fit'; i.e. when a case does not follow a similar causal pattern with other cases in a model. A qualitative researcher is normally well informed about each case under investigation, so if it happens that a case is deviant, i.e. does not conform to the researcher's causal model, that case is reserved and later on explained instead of simply ignoring it the way quantitative research does (Mahoney \& Goertz,2006). In such situation, the researcher will find out special factors that made the case to behave like that in the causal explanation. The question here is to explore why the case(s) did follow their own causal pattern. 
After obtaining the reasons, the researcher then discusses them thickly (Ragin, 2004).

\subsection{Quantitative Research: Meaning and Philosophical Foundations}

Quantitative social science research approach is the application of natural science principles, particularly, a positivist/empiricist approach in explaining social phenomena (Bryman, 1984; Cormack, 1991; Ercikan \& Roth, 2006). Positivism involves such principles as: setting operational definitions to concepts, ensuring objectivity by detaching from the subjects, striving for replication and establishing causality (Ercikan \& Roth, 2006). Unlike qualitative research which in principle approaches the subjects in their natural settings, quantitative research approach employs a procedure similar to that of a controlled experiment. Survey questionnaire is considered to be one of the most appropriate instruments that can meet the requirements of positivism. For example, through individual items in a questionnaire, concepts can be clearly operationalized, objectivity can be ensured through the use of self-administered questionnaire, replication can be carried out using the same instrument in other social settings, and through path analysis and regression techniques, causality can be established (Bryman, 1984).

Quantitative social researchers are interested in the 'effects-of-causes' rather than causes-of-effects as it is for qualitative research (Mahoney \& Goertz, 2006:228-231). In other words, with quantitative research, one seeks to estimate the average effect of one or more causes across a population of cases; and the explanation of specific outcomes in particular cases is not the central tenet of quantitative research approach. Questions such as 'what is the effect of economic development on national stability?' or 'what effect does a given increase in taxes have on people's purchasing power?' Quantitative research approach usually employs a variable-oriented strategy, where it seeks to assess the relationship between aspects of cases across a large sample of observations for the purpose of specifying general patterns that hold for a population (Ragin, 1987). Basically, quantitative research search for 'laws' and principles that can help to predict how the world works (Dharamsi \& Scott, 2009). It employs methods such as surveys, analysis of records, different types of archival data and census to collect data (Ragin, 1999 a).

We have seen that in qualitative research, the researcher is normally well informed about the cases under investigation to the extent that when a case displays a different causal pattern $\mathrm{s} / \mathrm{he}$ can find out how to explain the deviation/lack of fit. This is not the case in quantitative research. The researcher deals with many cases and has no enough information on individual cases. So when a particular case cannot be explained in a theoretical model is not considered to pose any serious problem as long as the model provides good estimates of parameters for the population as a whole (Mahoney \& Goertz, 2006; Ragin, 2004). So the researcher in such a situation cannot waste much of her/his time. This case is simply acknowledged and then ignored. Doing so raises hot debate. Qualitative researchers would claim that a case not conforming to the model needs to be 'explained' rather than simply being acknowledged (Ragin, 2004:138) as the latter entails explanation of only a small portion of the variation of interest while leaving the rest in the error term unexplained.

\subsection{What Are the Shortcomings of the Two Approaches?}

Qualitative research is seen by its opponents as merely an assembly of narration and personal impressions and thus, strongly subject to researcher bias. It is also argued that qualitative research lacks reproducibility, in that it is so personal to the researcher that there is no assurance that a different researcher would come to the same conclusions (Mays \& Pope, 1995). The approach is criticized for sticking too much to particulars such as individual voters, particular government units, specific cities, groups and so on; hence lacking generalizability, notwithstanding its ability to come up with large amounts of detailed information about a small number of cases (King, et al., 1994; Mays \& Pope, 1995). On the other hand, quantitative social research also suffers several shortcomings. As pointed out earlier in this paper, quantitative research methodologies are not sensitive to the complexities of social phenomena. Quantitative research builds on directly observable quantitative indicators and establishing causal relationships. Being so, it neither captures the phenomena in their full complexity nor facilitates an understanding of their contextual manifestation (Bryman, 1984). For instance, it presumes a considerable degree of understanding of the phenomenon of interest and often neglects aspects of the phenomenon that are unexpected. In doing so, it falls short of adequate explanation of the emerging issues in respect of the phenomenon under investigation. In addition, quantitative research tends to stick to the assumption that facts are true and the same (universal) for all people every time. Due to that orientation, it fails to capture people's unique ability to interpret their experiences, construct their own meanings and act on these. Lastly, because of the tendency of quantitative research to examine large number of cases, it lacks depth in explaining the phenomenon under investigation. (Carr, 1994). 
Table 1. Qualitative vs. quantitative research traditions - a summary

\begin{tabular}{|c|c|c|}
\hline Criteria & Qualitative research tradition & Quantitative research tradition \\
\hline Orientation/view & $\begin{array}{l}\text { Interpretivist: seeks to gain a deep } \\
\text { understanding and provide explicit } \\
\text { interpretation of a social phenomenon or a } \\
\text { particular case (it is thus, case-oriented). }\end{array}$ & $\begin{array}{l}\text { Positivist: seeks to provide a superficial } \\
\text { description of a large sample of } \\
\text { population and variables for the purpose } \\
\text { of } \\
\text { variable-oriented). }\end{array}$ \\
\hline $\begin{array}{l}\text { Nature of reality and } \\
\text { how it is constructed } \\
\text { (Ontology) }\end{array}$ & $\begin{array}{l}\text { Existence of multiple realities } \\
\text { /perspectives. Reality is socially } \\
\text { constructed and meaning is embedded in } \\
\text { the context of socio-cultural values and } \\
\text { institutions (context-specificity). }\end{array}$ & $\begin{array}{l}\text { Existence of one objective reality that can } \\
\text { be observed and explained through } \\
\text { properly organized scientific procedures } \\
\text { (universality). }\end{array}$ \\
\hline $\begin{array}{l}\text { Knowledge \& how it } \\
\text { is acquired } \\
\text { (Epistemology) }\end{array}$ & $\begin{array}{l}\text { Being interpretive, qualitative research } \\
\text { tradition accepts the multiple social } \\
\text { constructions of meaning and knowledge. } \\
\text { Truth is relative; meaning that ultimate } \\
\text { truth Knowledge is usually value-laden } \\
\text { and drawn from interpretation of what is } \\
\text { observed. }\end{array}$ & $\begin{array}{l}\text { What is accepted as 'knowledge' is } \\
\text { something that has been directly observed } \\
\text { by the senses; and it is theory-neutral } \\
\text { \&value-free. Objective knowledge (i.e. } \\
\text { facts) can be gained from direct } \\
\text { observation or experience, but is not } \\
\text { perfect. } \\
\text { hypotheses/assumptions, background } \\
\text { knowledge and values of the researcher } \\
\text { influence observations. }\end{array}$ \\
\hline $\begin{array}{l}\text { Approach and } \\
\text { purpose of research }\end{array}$ & $\begin{array}{l}\text { Inductive approach: seeks to explore, } \\
\text { describe, understand, explain, change } \\
\text { and/or evaluate. Explanation of social } \\
\text { phenomena is approached through analysis } \\
\text { of the frames of meanings of social actors } \\
\text { obtained from everyday } \\
\text { concepts/meanings/accounts. Findings are } \\
\text { specific to time and place. }\end{array}$ & $\begin{array}{l}\text { Deductive approach: Formulation \& } \\
\text { testing hypotheses; } \\
\text { General laws and theories guide } \\
\text { explanation and prediction. } \\
\text { Statistical generalization of the results is } \\
\text { possible }\end{array}$ \\
\hline Guide to & $\begin{array}{l}\text { No clear research question and hypotheses. } \\
\text { Inquiry is guided by a broad research } \\
\text { question that is refined as analysis } \\
\text { continues. }\end{array}$ & $\begin{array}{l}\text { There is an explicit research question and } \\
\text { hypotheses that are specified right at the } \\
\text { beginning of the study. }\end{array}$ \\
\hline $\begin{array}{l}\text { Participants/subjects } \\
\& \text { relationship with } \\
\text { researcher }\end{array}$ & $\begin{array}{l}\text { Research participants/subjects are active } \\
\text { and participate in constructing reality } \\
\text { /meaning with the researcher. }\end{array}$ & $\begin{array}{l}\text { Subjects are passive. The researcher is } \\
\text { detached and always strives to be } \\
\text { objective to avoid bias. }\end{array}$ \\
\hline Measurement $\&$ data & $\begin{array}{l}\text { Interpretation of words (verbal or textual) } \\
\text { and meanings to gain understanding of } \\
\text { phenomena under study is the key tenet of } \\
\text { this tradition. It refers to the what, how, } \\
\text { when and where of a thing, its essence and } \\
\text { atmosphere. Analysis is characterized by } \\
\text { 'thick' descriptions \&explanations }\end{array}$ & $\begin{array}{l}\text { Measurement: standard instruments } \\
\text { (validated) are used. Measures obtained } \\
\text { using indicators of concepts and data } \\
\text { quantified and analyzed numerically } \\
\text { through statistics. It refers to counts and } \\
\text { measure of things. Analysis is } \\
\text { characterized by 'thin' descriptions/ } \\
\text { explanations }\end{array}$ \\
\hline
\end{tabular}

\section{Qualitative Comparative Analysis (QCA): A Mediating Methodology?}

Qualitative Comparative Analysis (QCA) is regarded as a mid-way methodological strategy developed by Ragin (1987) in responding to the shortcomings of qualitative and quantitative social research (Verweij \& Noy, 2013). The methodology uses the principles of set theory, and it focuses on 'explicit connections between conditions' as opposed to quantitative methods such as regression analysis which focuses on 'tendential relationships or net effects' (Emmenegger, 2011:344). QCA involves a systematic analysis of similarities and differences across cases. It is used in macro social studies; or what other scholars call 'macroscopic comparative analyses' to 
examine the conditions under which a state of affairs is realized (Coverdill \& Finlay, 1995:458; Leech \& Onwuegbuzie, 2008:593).

As a theory-building approach, QCA allows the analyst to establish connections among previously established categories, also to test and to develop the categories further (Miles, 1994). QCA is mostly used in causal, macro-level applications to reanalyze secondary data collected by others (Emmenegger, 2011 ; Ragin, 1989; Ragin, 1994). However, it can be applied in 'micro sociological, non-causal, hermeneutically oriented analysis of interview data. . .' where 'several analyses, at various levels, follow each other, providing for examination of cases from different angles and accordingly, arriving at new ideas about their interrelations' (Rantala \& Hellström, 2001:88). Be it in causal or non-causal QCA applications, construction of a truth table is the first thing after preparation of data sets/data matrices. A truth table involves listing of all unique configurations of the study participants and situational variables appearing in the data, along with the corresponding 'observations' for each configuration (Miethe \& Drass, 1999). In the truth table, information about which configurations are unique to a category of the classification variable and which configurations are found in multiple categories can be provided (Leech \& Onwuegbuzie, 2008).

By comparing the numbers of configurations in these groups, an estimate of the extent to which for example, types of events, experiences, or the like are similar or unique. Then, the configurations are compared within a group, looking for commonalities that allow for further simplifications by identifying and eliminating unnecessary variables from configurations (Miethe \& Drass, 1999). A variable is considered as unnecessary if its presence or absence within a configuration has no effect on the outcome that is associated with the configuration (Leech \& Onwuegbuzie, 2008). Thus, qualitative comparative analysis produces case based rather than variable based findings (Ragin, 1989, 1994). The comparisons are repeated until no further reductions/simplifications can be done. Redundancies in the remaining reduced configurations are removed, which results in the final solution, i.e. a statement of the unique features of each category of the typology.

QCA is a case-oriented approach that considers each case holistically as a configuration of attributes (Ragin, 1999 b.; Benoît Rihoux, Rezsohazy, \& Bol, 2011). Specifically, qualitative comparative analysts assume that the effect of a variable may be different from one case to the next, depending upon the values of the other attributes of the case. By undertaking systematic and logical case comparisons, qualitative comparative analysts use the rules of Boolean algebra to identify commonalities among these configurations, thereby reducing the complexity of the typology. The goal of QCA is to achieve a typology that accepts heterogeneity within groups, and that explains categories as 'configurations of attributes' (Miethe \& Drass, 1999:10).

QCA methodology involves a dichotomization of both conditions and outcome. That is, 'present'(true) coded as 1 and 'absent' (false) coded as 0 in crisp set analysis (Ragin, 1987). However, this approach has been criticized as leading to loss of information which Ragin argues that it is not much. It is probably due to this weakness Ragin (2000) came up with fuzzy-set Qualitative Comparative Analysis (fs/QCA), which is the combination of fuzzy set theory and QCA. The fuzzy sets approach allows for partial membership in a set, as opposed to crisp set QCA which differentiates presence and absence of a condition or outcome. In fs/QCA therefore, membership scores are allowed between 0 (non-membership) and 1 (full membership). QCA in comparative case-oriented research is useful in specifying the scope conditions of theoretically competing causal mechanisms; that is, the circumstances or a set of institutional and political conditions under which a causal mechanism or set-theoretic relationship between causal mechanisms empirically holds (Aus, 2009:4).

\subsection{QCA and Causal Complexity}

It is a usual claim that '[s]ocial phenomena are complex' (Ragin, 1997:19). This complexity is brought about by social diversity, which has also different manifestations. Things in the social world happen in various ways that astonish not only ordinary people but also the scientists. Imagine a divorce of a once happily living married couple one would think they will continue living that way in the whole of their life; or a suicide bomber deciding to end his/her life killing maliciously many other innocent people and destroying public property. Events such as these are not easily explainable. This is what causal complexity entails. The bottom line here is; it is usually impossible to single out one variable as a causal explanation of a particular social phenomenon. Causal complexity therefore remains one of the major challenges facing comparative social scientists. The universe of cases from which one may choose to focus on is limited and at the same time, the hypotheses suggested at the theoretical level display a complex interplay of variables producing the outcome (the phenomenon) to be explained (Schneider \& Wagemann, 2006 ).

\subsection{Meaning and Forms of Causal Complexity in the Social Science}

Social scientists explain causal complexity in various ways. For example, Jervis (1997:35) considers it as a 
situation whereby 'the effect of one variable or characteristic can depend on which others are present'. That is, a variable may sometimes require the presence or absence of other variable(s) for it to produce an outcome (Ragin, 2000). Causal complexity entails a situation in which the effect of one variable or characteristic can depend on which others are present, or in which an outcome results from several different combinations of conditions.

\subsubsection{Complexity Resulting from Context}

This form of complexity is brought about by variations in the environment of causal process. For instance, the presence or absence of one independent variable mitigates or sometimes, nullifies the impact of another (Braumoeller, 2003:4). If, as $\mathrm{X} 1$ increases, variation in $\mathrm{X}_{\mathrm{n}}$ has a decreasing impact on $\mathrm{Y}$, the assumption of 'additivity' cannot reflect the way in which the causal process is or should be predicted. This form of complexity is based on contexts in which the conditions and outcome operate. The argument here is that the same causal conditions may not operate in the same way in all contexts and all cases. This can be illustrated as for example; $X 1$ produces $Y$ but only in the presence of $X 2$. Another context can be $X 1$ produces $Y$ but in the presence of $X 2$ and absence of $X 3$. Ragin (1987:20) on the other hand, describes causal complexity as a situation where an 'an outcome results from several different combinations of conditions'. That is, conditions that produce a particular outcome are viewed not in isolation but as combinations of conditions that produce the 'whole' (outcome) in question.

\subsubsection{Multiple Conjunctural Causation/Multiple Causality}

This form of complexity is common in case-oriented research (Braumoeller, 2003:3; King, et al., 1994:87; Rihoux et al, 2011).The causal relationship can be illustrated as: $X 1$ and $X 2$ and $X 3$ produce $Y$ (Ragin, 1987). In conjunctural causation, outcomes are explained in terms of combinations or conjunctures of causal conditions(Ragin, 2000:40). According to Ragin, most macro- political issues of interest to comparative social scientists are characterized by causal complexity. He gives an example of large-scale political changes such as collapse of a political regime or rapid decline in citizens' support to a political regime which usually results from combinations of conditions.

In Patrick Emmenegger's analysis of the determinants of job security regulations in Western democracies for example, he found three different 'paths' leading to the outcome (high levels of job security regulations), each of them covering a different group of countries, a characteristic he terms 'equifinality' (Emmenegger, 2011:338; George \& Bennett, 2005; Mahoney \& Goertz, 2006:144-145). Causal equifinality entails several causes acting independently of each other to produce, each on its own, a particular effect (Gerring, 2005:164). However, he argues that it is only the combinations of conditions that can plausibly account for cross-national variations in the level of the outcome (job security regulations) and not the non-overlapping contribution of each independent variable which takes into consideration the net effects of the variables.

\subsubsection{INUS Conditions}

INUS conditions means causal conditions that are insufficient but necessary parts of causal recipes which are themselves unnecessary but sufficient for producing the outcome (Mahoney \& Goertz, 2006; Ragin, 2008). Putting it in other words, INUS conditions imply unsatisfactory but important parts of a condition which is itself unnecessary, but sufficient for the occurrence of the effect (Mackie, 1980; Ragin, 1987, 2000). This happens in a situation where conditions must combine for them to be able to produce an outcome. Let us consider a hypothetical example of low level of education (E) as a cause for person's unemployment (U), and consider six hypothetical combinations of causes as together being sufficient to produce the outcome $U$. In such hypothetical combinations then, we can say, either low level of education (E) and Lack of job openings (J) and Lack of investment (I) produce U; or living in the rural (R) and Irrelevant skills (S) and lack of job preferences (P) produces U. Together, these are unnecessary but sufficient to the person's unemployment (since many other collections of conditions certainly could have led to the person's unemployment. Put in a form of equation (which we will call a logical statement), the following can be conceptualized: E.J.I + R.S.P $\rightarrow$ U; where the 'dot' symbol in between conditions represents a logical AND, the 'plus' sign logical OR and the 'arrow' indicates 'to produce'.

If we look at the above logical statement carefully, we can learn that this is a very complex statement of causal explanation. However, in the equation, none of the six single causes is either necessary or sufficient in producing an outcome. It is also clear that none of them is a general cause (i.e. acts as a cause in all instances of the outcome) and none is capable of producing outcome on its own. Each of the six conditions in the hypothetical logical statement is not 'singularly sufficient' (Ragin, 2000:95). It must combine with the other conditions to constitute a sufficient condition for an outcome. So in the logical statement $\mathrm{E}$ and $\mathrm{J}$ and I produce $\mathrm{U}$ OR R and S and $\mathrm{P}$ produce $\mathrm{U}$; $\mathrm{E}$ is an insufficient (since by itself would not have caused the person's unemployment (U), but 
the unemployment would not have happened without it, everything else being equal). However, E is a non-redundant part of the condition which is itself unnecessary (as something else could have also caused the person's unemployment) but sufficient for the occurrence of the effect (U). To further clarify the statement, low level of education (E) is regarded as an INUS condition for the occurrence of the person's unemployment (U) because it is neither individually necessary nor individually sufficient for an outcome but it is one of the causes in a combination of causes that together are sufficient for occurrence of an outcome and in the illustration, the person's unemployment as we have just explained above based on Mackie (1980), Ragin $(1987 ; 2000 ; 2008)$ and Mahoney \& Goertz (2006). This analytical approach contrasts with the net effects thinking that is common in the conventional quantitative social science research. In addition, QCA facilitates a form of counterfactual analysis that is grounded in case-oriented research. QCA and particularly, fs/QCA provides new powerful analytical approaches to social scientists. Fuzzy set Qualitative Comparative Analysis (fs/QCA) combines both qualitative and quantitative analysis techniques in operationalization of concepts in social inquiry.

\subsection{So, What Does QCA Brings in to Mediate the Tensions?}

Qualitative Comparative Analysis and particularly, fuzzy set QCA, involves calibration of set membership (Glaesser \& Cooper, 2013; Ragin, 2007; Thiem \& Duşa, 2013; Wagemann \& Schneider, 2007). Set membership scores are useful in the analysis of consistency with 'sufficiency' and 'necessity' in QCA (Glaesser \& Cooper, 2013:2). Fuzzy-set calibration can be done either (1) through direct assignment, whereby fuzzy-set membership scores are derived from base variable values based on the researcher's or another expert's arbitrary judgment; or (2) through transformational assignment which involves mapping of base variable values into the unit interval with the aid of continuous functions for which only minimal information is provided by the researcher (Thiem \& Duşa, 2013:51). The main distinction between these two approaches of calibration therefore emanates from the same difference that exists between discrete and continuous random variables in statistics (Thiem \& Duşa, 2013). Calibration makes fuzzy sets superior and in many ways, resemble to conventional measures. Fuzzy sets are used in both quantitative (variable-oriented) and qualitative (case-oriented) social science; and they are midway strategy to offset the qualitative-quantitative tension on measurement. Fuzzy sets stay somewhere between qualitative and quantitative approaches in that full membership (1.0) and full non-membership (0.0) indicate qualitative states, while values in between the two qualitative states are different degrees of membership (Ragin, 2007; Wagemann \& Schneider, 2007). The degrees of membership range from: being 'more out' (closer to 0.0), 'neither in nor out' (0.5) to 'more in' (closer to 1.0). Fuzzy sets are considered to be both qualitative and quantitative because of their being case-oriented (by focusing on sets and set membership and treating cases as interpretable wholes); and variable oriented (because of their tendency to allow for degrees of membership). The tendency of fuzzy sets to allow for various degrees of membership provides for 'fine-grained variations across cases', hence, provides a basis for precise measurement, what is cherished by quantitative researchers (Ragin, 2008b:10). However, QCA and particularly fs/QCA is not a compromise between the two extremes, rather, it surpasses a great deal of their limitations (Wagemann \& Schneider, 2007). Our argument in the preceding paragraph is that through calibration of set membership and the application of set theory, QCA does some kind of measurement while maintaining case-sensitivity. We have also argued in the previous paragraphs that qualitative research (and especially, case studies based on single cases) suffers from little basis for causal generalization despite its richness in explanation (Mahoney, 2003; Ragin, 1997, 2000; Schneider \& Wagemann, 2006). However through comparison of cases, cross-case evidence can be achieved hence, increasing the probability of generalizing the findings to other comparable cases and contexts.

The analysis of necessary and sufficient conditions in QCA works on causal complexity that emanates from social diversity. A causal factor $(\mathrm{X})$ is a necessary condition if the outcome $(\mathrm{Y})$ is occurring only if $\mathrm{X}$ exists, whereas, a causal factor $(\mathrm{X})$ is a sufficient condition if the outcome $(\mathrm{Y})$ always occurs when $\mathrm{X}$ exists (Blatter, 2012). More precisely, a sufficient condition is itself capable of producing an outcome (Y); while a necessary condition (X) must be present for a particular outcome (Y) to occur. However, $\mathrm{Y}$ can also occur in the absence of $\mathrm{X}$. In other words, although $\mathrm{X}$ always leads to $\mathrm{Y}$, it is also possible for $\mathrm{Y}$ to occur without $\mathrm{X}$. Similarly in sufficiency, $\mathrm{Y}$ does not always have to occur if $\mathrm{X}$ exists. In other words, although $\mathrm{Y}$ is not possible without $\mathrm{X}, \mathrm{X}$ does not always lead to Y (Blatter, 2012:12). In order to find out whether a condition is necessary, the analyst needs to operate backwards from the instances of outcome to the identification of causes. To assess sufficiency, the researcher moves forth from the conditions to the outcomes to identify conditions which are followed by an outcome (Kitchener et al, 2002). If we consider our hypothetical example of unemployment (p.11), Low level of education (E), Lack of job openings (J), lack of investment (I), living in the rural (R), irrelevant skills (S) and Lack of job preferences (P) are said to be the possible causes of unemployment (U). If we formulate some logical statements or call them equations, we can see how necessity and sufficient concepts operate. We will use 
$\mathrm{E}$ as our variable of explanation in the following four logical statements:

$$
\begin{gathered}
\mathrm{E} \leftarrow \mathrm{U} \\
\text { E.J.I.S.P } \leftarrow \mathrm{U} \\
\mathrm{E}+\mathrm{I}+\mathrm{P} \rightarrow \mathrm{U} \\
\text { E.J.I }+ \text { R.S.P } \rightarrow \mathrm{U}
\end{gathered}
$$

The indication of the first logical statement is that $\mathrm{E}$ is a necessary and sufficient condition for the outcome (U). In the second, $\mathrm{E}$ is necessary but not sufficient for causing $\mathrm{U}$. It has to combine with the other causes and together to attain sufficiency for producing $\mathrm{U}$. In this logical statement, presence of E, J, I, S and P is a necessary condition for the outcome $U$ to occur, denoted by a reversed arrow $(\leftarrow)$. The reversed arrow in the logical statement however, does not mean a reverse of the relationship. Rather, it just denotes a logical implication (Schneider \& Wagemann, 2010) that wherever we find U we will also find the (combined) condition E.J.I.S.P which is necessary for the outcome $U$. In the third statement, any of the three conditions can cause $U$. That being the case therefore, $\mathrm{E}$ (as for the other two conditions) is sufficient but not necessary in the occurrence of U. With the last logical statement, complexity has increased. It is argued that causal relations like this are the ones which are common in social phenomena (Ragin, 2000). None of the six single causes is either necessary or sufficient for the outcome $(\mathrm{U})$. In addition, none of them is capable of producing an outcome on its own. Thus $\mathrm{E}$ is an INUS condition which I have discussed in the previous paragraphs.

\subsection{Limitations of $Q C A$}

The first limitation is based on the fact that QCA involves dichotomization of data for both the conditions and outcome based on (in most cases) arbitrarily established thresholds; and so, it appears to be a simplification of data which leads to unnecessary loss of information (Bollen, Entwisle, \& Alderson, 1993; Goldthorpe, 1997; Rihoux, 2003). However, it is argued that simplification of data through dichotomization helps in the understanding of complexity in comparative social studies (Rihoux, 2003). Despite the fact that any empirical scientific inquiry (qualitative, quantitative or both) necessarily involves some kind of simplification (King, et al., 1994), dichotomization needs to be as much as possible theoretically-informed and in any case, researcher may attempt employing QCA first and then fuzzy sets and compare the results. This can be useful in reducing oversimplification of data and loss of information (Rihoux, 2003).

The second limitation is in connection with limited diversity. QCA approach faces a dilemma in deciding number of relevant conditions to be included in the analysis of a particular outcome. Why?, because the number of cases of interest to social researcher are limited to a medium-size $\mathrm{N}$ (c.25-50) relative to the complex interplay of variables postulated by the hypotheses at the theoretical level (Schneider \& Wagemann, 2006:751). When one uses a small-N research design, the problem of limited diversity is raised with QCA, as the number of logically possible combinations of conditions quickly overwhelms the number of empirically observed combinations (Ragin, 1987). For example, consider a study on the causes of political conflicts in Sub-Saharan Africa. Regardless to how broad is the definition of political conflicts used, the universe of relevant cases will still be limited, taking into consideration that the total number of countries in the universe of sub-Saharan countries is around 47. On the other hand, if we can explore what the literature says about causes of political conflicts, certainly an elaborate list of possible and plausible hypotheses on what fosters political conflicts will be found. So, comparative social researchers often face the challenge of actually thinking of the number of conditions to include in the analysis, otherwise if they include too many conditions to match with the number of cases, it will result into excessive logical remainders (possible combinations without cases).

\section{Conclusion}

In this paper, we have discussed the two styles of (qualitative and quantitative) research in social science research and addressed their philosophical and methodological underpinnings. We have also highlighted the unresolved tensions between the quantitative and qualitative researchers as to which one of the two traditions is more appropriate than the other. The discussion culminates by examining whether QCA or not can have a place in the mediation of the tensions. The conclusions we draw in view of the discussions in the paper are that (1) both qualitative and quantitative research traditions are equally scientific and relevant in social science research. Being so, choice can be made to use either of the two approaches or combine them (Onwuegbuzie \& Leech, 2005) depending on the nature and purpose of the study. (2) The attempt to resolve the qualitative- quantitative tensions introduced for the first time by Ragin (1987) through QCA is promising despite its newness. QCA has proved to be appropriate for theory-driven work; and because it allows for cross-case, within-case and empirical reality vs. theoretical ideal types comparisons; it provides for more plausible approaches to explanation of causal 
relationship. However, QCA should not be regarded as a substitute of the two traditions but a methodological strategy that attempts to complement them.

\section{References}

Atkinson, P. (1988). Ethnomethodology: A critical review. Annual Review of Sociology, 14, 441-465. Retrieved from http://www.jstor.org/stable/2083327 http://dx.doi.org/10.1146/annurev.so.14.080188.002301

Aus, J. P. (2009). Conjunctural causation in comparative case-oriented research. Quality \& Quantity, 43(2), 173-183. http://dx.doi.org/10.1007/s11135-007-9104-4

Blatter, J. (2012). Ontological and Epistemological Foundations of Causal-Process Tracing: Configurational Thinking and Timing. Paper presented at the ECPR Joint Sessions in Antwerp, 10 -14 April 2012. Retrieved from http://www.unilu.ch/files/blatter-ecpr-antwerp-final.pdf

Bogdan, R., \& Biklen, S. K. (1998). Qualitative research for education: An introduction to theory and methods. Boston: Allyn \& Bacon.

Bollen, K. A., Entwisle, B., \& Alderson, A. S. (1993). Macrocomparative research methods. Annual Review of Sociology, 19, 321-351. Retrieved from http://www.jstor.org/stable/2083391 http://dx.doi.org/10.1146/annurev.so.19.080193.001541

Braumoeller, B. F. (2003). Causal complexity and the study of politics. Political Analysis, 11(3), 209. http://dx.doi.org/10.1093/pan/mpg012

Bryman, A. (1984). The debate about quantitative and qualitative research:a question of method or epistemology? British Journal of Sociology, 35(1), 75-92. Retrieved from http://www.jstor.org/stable/590553 http://dx.doi.org/10.2307/590553

Carr, L. T. (1994). The strengths and weaknesses of quantitative and qualitative research: what method for $\begin{array}{lllll}\text { nursing? } & \text { Journal }\end{array}$ http://dx.doi.org/10.1046/j.1365-2648.1994.20040716.x

Cormack, D. S. (1991). The research process. Oxford: Black Scientific.

Coverdill, J. E., \& Finlay, W. (1995). Understanding mills via mill-type methods: An application of qualitative comparative analysis to a study of labor management in southern textile manufacturing. Qualitative sociology, 18(4), 457-478. http://dx.doi.org/10.1007/BF02404491

Della Porta, D. (2008). Comparative analysis: case-oriented vs. variable-oriented research. In M. Kieting, \& D. Della Porta (Eds.), Approaches and Methodologies in the Social Sciences: A Pluralist Perspective (pp. 198-222). Cambridge: Cambridge University Press. http://dx.doi.org/10.1017/CBO9780511801938.012

Dharamsi, S., \& Scott, I. (2009). Quantitative and qualitative research. Canadian Family Physician, 55(8), 843-844. Retrieved from http://www.cfp.ca/content/855/848/843.full.pdf

Emmenegger, P. (2011). Job security regulations in Western democracies: A fuzzy set analysis. European Journal of Political Research, 50(3), 336-364. http://dx.doi.org/10.1111/j.1475-6765.2010.01933.x

Ercikan, K., \& Roth, W. M. (2006). What good is polarizing research into qualitative and quantitative? Educational Researcher, 35(5), 14-23. http://dx.doi.org/10.3102/0013189X035005014

Frankfort-Nachmias, C., \& Nachmias, D. (1992). Research Methods in the Social Sciences. London: Edward Arnold.

Garfinkel, H. (1967). Some rules of correct decision making that jurors respect. Studies in ethnomethodology, 104-115.

George, A. L., \& Bennett, A. (2005). Case studies and theory development in the social sciences. The MIT Press.

Gerring, J. (2005). Causation: A unified framework for the social sciences. Journal of Theoretical Politics, 17(2), 163-198. http://dx.doi.org/10.1177/0951629805050859

Glaesser, J., \& Cooper, B. (2013). Exploring the consequences of a recalibration of causal conditions when assessing sufficiency with fuzzy set QCA. International Journal of Social Research Methodology, (ahead-of-print), 1-15. http://dx.doi.org/10.1080/13645579.2013.769782

Glaser, B. G., \& Strauss, A. L. (1967). The discovery of grounded theory: Strategies for qualitative research. New York: Russell Sage Foundation.

Goldthorpe, J. H. (1997). Current issues in comparative macrosociology: A debate on methodological issues. 
Comparative Social Research, 16, 1-26.

Jervis, R. (1997). System effects: Complexity in social and political life. New Jersey: Princeton University Press.

Katz, J. (1982). Poor people’s lawyers in transition. Rutgers University Press, New Brunswick, NJ.

King, G., Keohane, R. O., \& Verba, S. (1994). Designing social inquiry: Scientific inference in qualitative research. Princeton University Press.

Kitchener, M., Beynon, M., \& Harrington, C. (2002). Qualitative comparative analysis and public services research: Lessons from an early application. Public Management Review, 4(4), 485-504. http://dx.doi.org/10.1080/14616670210163033

Leech, N. L., \& Onwuegbuzie, A. J. (2008). Qualitative data analysis: A compendium of techniques and a framework for selection for school psychology research and beyond. School Psychology Quarterly, 23(4), 587. http://dx.doi.org/10.1037/1045-3830.23.4.587

Long, A. F., \& Godfrey, M. (2004). An evaluation tool to assess the quality of qualitative research studies. International Journal of Social Research Methodology, 7(2), 181-196. http://dx.doi.org/10.1080/1364557032000045302

Mackie, J. L. (1980). The cement of the universe: A study of causation. Oxford University Press, USA. http://dx.doi.org/10.1093/0198246420.001.0001

Mahoney, J. (2003). Strategies of causal assessment in comparative historical analysis. Comparative historical analysis in the social sciences, 337-372.

Mahoney, J., \& Goertz, G. (2006). A tale of two cultures: Contrasting quantitative and qualitative research. Political Analysis, 14(3), 227-249. http://dx.doi.org/10.1093/pan/mpj017

Marshall, C., \& Rossman, G. (1999). Designing Qualitative research. London: Sage Publications

Mays, N., \& Pope, C. (1995). Qualitative research: rigour and qualitative research. BMJ 311(6997), $109-112$. Retrieved from http://www.ncbi.nlm.nih.gov/pmc/articles/PMC2550154/pdf/bmj2500600-2550043.pdf http://dx.doi.org/10.1136/bmj.311.6997.109

Miethe, T. D., \& Drass, K. A. (1999). Exploring the social context of instrumental and expressive homicides: An application of qualitative comparative analysis. Journal of Quantitative Criminology, 15(1), 1-21. http://dx.doi.org/10.1023/A:1007550704282

Miles, M. B., \& Weitzman, E. A. (1994). Choosing computer programs for qualitative data analysis. In M. B. Miles, \& M. Huberman (Eds.), Qualitative data analysis: An expanded sourcebook (2nd ed., pp. 311-317). Thousand Oaks, CA: Sage.

Mishler, E. G. (1979). Meaning in context: Is there any other kind? Harvard Educational Review, 49(1), 1-19. Retrieved from http://her.hepg.org/content/b748n4133677245p/

Mouton, J. (1986). Mouton, J. 1986. The philosophy of qualitative research. In M. Ferreria, et al. (Eds.), Module 3: Introduction to qualitative research methods. Pretoria: Human Sciences Research Council. Proceedings of the First HSRC Winter School in Research Methodology, 30 June to 10 July..

Onwuegbuzie, A. J., \& Leech, N. L. (2005). On becoming a pragmatic researcher: The importance of combining quantitative and qualitative research methodologies. International Journal of Social Research Methodology, 8(5), 375-387. http://dx.doi.org/10.1080/13645570500402447

Ragin, C. C. (1987). The Comparative Method: moving beyond qualitative and quantitative strategies. Berkeley: University of California Press.

Ragin, C. C. (1989). The comparative method: Moving beyond qualitative and quantitative strategies. Univ of California Pr.

Ragin, C. C. (1994). Introduction to qualitative comparative analysis. The comparative political economy of the welfare state, 299-317.

Ragin, C. C. (1997). Turning the tables: How case-oriented research challenges variable-oriented research. In H. E. A. C. Brady (Ed.), Comparative Social Research (Vol. 16, pp. 27-42).

Ragin, C. C. (1999a). Using qualitative comparative analysis to study causal complexity. Health Services Research, 34(52), 1225-1239. Retrieved from http://www.ncbi.nlm.nih.gov/pmc/articles/PMC1089061/

Ragin, C. C. (1999b). The distinctiveness of case-oriented research. Health Services Research, 34(52), 
1137-1151. Retrieved from http://www.ncbi.nlm.nih.gov/pmc/articles/PMC1089057/

Ragin, C. C. (2000). Fuzzy-set social science. Chicago: University of Chicago Press.

Ragin, C. C. (2004). Turning the Tables: How Case-Oriented Research Challenges. In H. E. Brady, \& D. Collier (Eds.), Rethinking social inquiry: Diverse tools, shared standards (pp. 123-138). Roman and Littlefield Publishers Inc.

Ragin, C. C. (2007). Fuzzy sets: calibration versus measurement Methodology volume of Oxford handbooks of political science. $\quad$ Retrieved from http://toktok.persiangig.com/other/Calibration\%20fuzzy\%20measurement.pdf

Ragin, C. C. (2008). What is Qualitative Comparative Analysis? University of Arizona. Retrieved from http://eprints.ncrm.ac.uk/250/1/What_is_QCA.pdf

Rantala, K., \& Hellström, E. (2001). Qualitative comparative analysis and a hermeneutic approach to interview data. International Journal of Social Research Methodology, 4(2), 87-100. http://dx.doi.org/10.1080/13645570118545

Rihoux, B. (2003). Bridging the gap between the qualitative and quantitative worlds? A retrospective and prospective view on qualitative comparative analysis. Field Methods, 15(4), 351-365. http://dx.doi.org/10.1177/1525822X03257690

Rihoux, B., Rezsohazy, I., \& Bol, D. (2011). Qualitative comparative analysis (QCA) in public policy analysis: an extensive review. Ger Policy Stud, 7(3), 9-82. Retrieved from http://www.spaef.com/file.php?id=1317

Schneider, C. Q., \& Wagemann, C. (2006). Reducing complexity in Qualitative Comparative Analysis (QCA): Remote and proximate factors and the consolidation of democracy. European Journal of Political Research, 45(5), 751-786. http://dx.doi.org/10.1111/j.1475-6765.2006.00635.x

Schneider, C. Q., \& Wagemann, C. (2010). Standards of good practice in qualitative comparative analysis (QCA) $\begin{array}{lllll}\text { and fuzzy-sets. } & \text { Comparative } & \text { Sociology, } & 9(3), & \text { 397-418. }\end{array}$ http://dx.doi.org/10.1163/156913210X12493538729793

Smith, J. K. (1983). Quantitative versus qualitative research: An attempt to clarify the issue. Educational Researcher, 12(3), 6-13. Retrieved from http://www.jstor.org/stable/1175144 http://dx.doi.org/10.3102/0013189X012003006

Taylor, C. (1985). Philosophy and the human sciences (Vol. 2). Cambridge Univ Pr. http://dx.doi.org/10.1017/CBO9781139173490

Thiem, A., \& Duşa, A. (2013). Fuzzy-Set QCA Qualitative Comparative Analysis with R (pp. 51-81). Springer. http://dx.doi.org/10.1007/978-1-4614-4584-5_4

Verweij, S., \& Noy, C. (2013). Set-theoretic methods for the social sciences: a guide to qualitative comparative analysis. International Journal of Social Research Methodology, 16(2), 165-169. http://dx.doi.org/10.1080/13645579.2013.762611

Wagemann, C., \& Schneider, C. Q. (2007). Standards of good practice in qualitative comparative analysis (QCA) and fuzzy-sets. Retrieved from http://www.compasss.org/wpseries/WagemannSchneider2007.pdf

\section{Copyrights}

Copyright for this article is retained by the author(s), with first publication rights granted to the journal.

This is an open-access article distributed under the terms and conditions of the Creative Commons Attribution license (http://creativecommons.org/licenses/by/3.0/). 